In a combined session on plant diseases and purity of stocks, Mr. W. C. Moore stressed very strongly the importance of ensuring really healthy plant material before it is moved from country to country. The introduction of major pests with plant material is unfortunately only too well known and common an experience. Virus diseases are one of the most difficult problems that horticulturists now have to face, and in his paper on the serological diagnosis of plant diseases caused by virus, which he supported with a film, Prof. E. van Slogteren, of the Netherlands, showed how many virus diseases can at any rate be diagnosed by serological methods, a diagnosis which is independent of the symptoms of the plant.

A paper of great interest on the use of 'Krilium' as a soil conditioner, by Dr. A. J. Lloyd and Dr. C. E. Morgan, of Monsanto Chemicals, Ltd., was presented in this session, and a film was shown demonstrating the power of 'Krilium' to retain a crumbly. soil structure and for the treated soil to retain drops of water without disintegrating. 'Krilium' was described by the authors as "a new synthetic polymeric electrolyte of a resin type, which by reason of its high anion potential, possesses large numbers of reactive groups in the molecule". It is understood that tests are proceeding in Great Britain, and it is to be hoped that soon this material, which is already on the market in the United States, will also be available in Britain.

In a Congress to which more than a hundred different papers were presented by speakers from twenty-seven different countries, it is obviously impossible to do more than touch on a few of the aspects of the very varied mass of material which was available. The report of the Congress will be published through the Royal Horticultural Society, Vincent Square, London, S.W.I, in due course.

In the field of the nomenclature of horticultural plants, a revised International Code was worked out during the Congress and will shortly be published as an interim code prior to submission to the next Horticultural Congress, which it is anticipated will be held in Holland in 1955 or 1956. The Congress also laid great stress on the importance of the registration of the names of cultivated varieties, and in a resolution recommended that an International Registration Authority should be set up as soon as practicable for each genus or group of genera in which cultivated varieties are numerous. The Congress also passed unanimously two resolutions on nomenclature for transmission to the next International Rotanical Congress. It put on record that it was "strongly of the opinion that the interest of increased stability in the nomenclature of cultivated plants would be served by incorporation into the International Code of Botanical Nomenclature of the proposals for Nomina Specifica Rejicienda set out in Taxon I, No. 5 (1952) and urged their adoption at the next International Botanical Congress". It also recommended in a resolution that any provision of this nature should "allow for the rejection of certain earlier homonyms as well as earlier synonyms, and while appreciating the technical difficulties involved, urged the appropriate botanical authorities to make every effort to overcome them". Mr. J. S. L. Gilmour, director of the Cambridge Botanic Garden, was appointed chairman of the International Committee for the Nomenclature of Cultivated Plants.
Other resolutions of the Congress were passed (1) in favour of the establishment of a horticultural bureau in the Food and Agriculture Organization; (2) in support of the recommendations of the International Plant Protection Convention and for increased facilities for the exchange of experimental material between country and country ; (3) in support of the encouragement of research into the fundamental problems of plant physiology ; and (4) for the setting up of a small working party for considering an international method for recording light values on the lines of the Dutch Committee.

Patrick M. Synge

\section{CHEMICAL RESEARCH LABORATORY, TEDDINGTON OPEN DAYS}

FOR the sixth year in succession the Chemical Research Laboratory, Teddington, of the Department of Scientific and Industrial Research, held a series of open days to which the director invited representatives of industry, universities and government departments. This year the open days were during September 23-26, and the attendance at all sessions indicated that there is no slackening of interest in this annual event.

A special feature this year was the new radiochemical building which has been specially designed and constructed, under the supervision of the Ministry of Works, for work with radioactive materials. It incorporates many modern features which make it one of the finest of its kind in Great Britain both for work with radioactive materials and for general chemical research. This building, with its associated pump house and tank farm, occupies an area of some twelve thousand square foet sitéd about a hundred yards from the main Laboratory block and is constructed of red brick with stone facing to conform to other buildings in the area. It comprises administrative offices, laboratories, plant room and service void, and pump house and tank farm. The administrative offices form a single-story section near the main entrance to the building and comprise an entrance hall, offices, conference room (also used as staff room), and cloakrooms which are provided with special facilities for changing and washing.

The main part of the building consists of two large laboratories and a number of smaller rooms divided, in part, by a central passage. Immediately beyond the cloakrooms and on one side of the passage are two laboratories concerned with research on the application of ion-exchange resins to the separation of metals. In these rooms an exhibit showed the development of a method for separating gold from other metals, such as iron, copper, silver, nickel, cobalt and zinc, in cyanide solution by an anionexchanger. In this process, gold is removed from the resin by eluting with a mixture of acetone and hydrochloric acid. The other metals are eluted with aqueous solutions of salts such as sodium cyanide and potassium thiocyanate.

On the opposite side of the passage from the foregoing laboratories is a suite of rooms dealing with the measurement of radioactivity and allied topics. These laboratories comprise a counting room completely screened from electrical interference, a main 
laboratory for the measurement of carbon-14 (including apparatus for low-activity measurements and a microscope for scrutinizing tracks on photographic plates), and a dark-room showing apparatus for the determination of radioactivity by measurement of scintillation in a liquid medium using solutions of $p$-terphenyl as the scintillator for radioactive material. A number of other items used in measurements of activity were shown in an adjoining laboratory.

Beyond the rooms already mentioned is a group of small laboratories and rooms. These laboratories, which can also be used as offices, are designed for one worker or for special purposes. Exhibits shown in two of these rooms included an automatic resin-life tester for determining how long an ion-exchange resin will stand up to continual re-use, and an apparatus for the continuous determination of metals by a polarographic method. Two further rooms contain balances and physical apparatus used in analytical work. Of special note is a nephelometer for turbidimetric determination. Beyond these small rooms is a large analytical laboratory containing eight double-benches, ancillary fume-chambers, dry benches for furnaces, washing-up sinks and built-in desks down each side of the laboratory. This laboratory deals with analyses of minerals and ores and with research on analytical methods. An exhibit of chromatographic methods using paper strips and columns was shown here, and particularly noteworthy was the method developed for determination of niobium and tantalum in minerals, ores and other substances. A small adjoining laboratory is devoted exclusively to fluorimetric methods, while a larger room is concerned with the separation of metals on paper strips using radioactive tracers, which are detected and determined on a special scanner built in the Radiochemical Group for this purpose.

The rest of the laboratory space is used for research work on the extraction and recovery of valuable metals from minerals and ores. A large room is available for operating with larger quantities of material than is possible in an ordinary laboratory. This large laboratory contained exhibits dealing with ionexchange methods, precipitation under $p H$ control and other techniques. Associated with this work are three smaller laboratories for research and control work, and a grinding room. The grinding room includes an ore storage annexe and contains a ball mill, hammer mill, mechanically operated screens, and an electromagnetic separator for preliminary ore treatment. 'This room is provided with a separate ventilation system to guard against hazard due to dust.

The plant room contains the machinery for ventilation and other items. Incoming air is filtered, washed and warmed before passing to the laboratories. Air is extracted through the fume chambers in the laboratories and passes through an electrostatic precipitator before ejection to the atmosphere through a 60 -ft. chimney. This ventilation system is designed to provide at least 80 linear feet of air a minute through the fume chambers. A service void forms a second story to most of the building, and houses all the ducting and services. It provides a very colourful but orderly sight, and repairs can be carried out w. th minimum disturbance to the laboratories underneath.

The disposal of liquid effluent has also been carefully considered. All liquid waste from the laboratories passes through polythene piping to one of three stainless-steel delay tanks (500 gal.), where it is monitored for radioactivity. The liquid is then either left to allow time for activity to decay while the other two tanks are used, or pumped to one of two larger tanks (5,000 gal.) for dilution, or pumped directly to the drain, depending on the activity present. Provision is also made for chemical treatment in the smaller tanks and disposal by tank truck if necessary.

In the Corrosion Group of the Chemical Research Laboratory, work on the high-temperature corrosion of steel has been supplemented by a new research on oxidation by flue gases; this is intended to assist in the development of a ferritic steel suitable for boiler superheater tubes operating at temperatures above the present normal maximum. The apparatus used consists of a tubular furnace in which the weight increase of several specimens can be measured in situ.

An interesting exhibit was an automatically controlled apparatus of the weatherometer type for accelerated corrosion testing. Constructed of 'Perspex', this permits continuous or intermittent exposure of specimens to spray (simulating either industrial or marine atmospheres) and infra-red and ultra-violet radiation as desired. A recently recognized ('filiform') type of corrosion which appears as worm-like tracks on plain or lacquered steel plates is being investigated; examples produced in the laboratory were exhibited. The mechanism of corrosion inhibition by sodium benzoate and potassium chromate is being studied by radioactive tracer methods and by electrode potential decay curves. The practical application of inhibitors has been extended by the formulation of corrosion-inhibitive greases and thixotropic pastes. In electrochemical studies of paint films on immersed steel, special attention has been given to the estimation of the amount of water absorbed by the paint.

The Pure Metals Committee of the Chemistry Research Board continually collects and examines information on the availability of metals of high purity and, in addition, carries out analyses of such materials. In certain cases samples of the purest obtainable metals are kept in stock, and these can be made available to workers in other laboratories for their researches. At present twenty-thrce metals are kept, twenty-two of which were shown in the exhibit of the Inorganic Group. Also on view were samples of highly pure germanium and germanium dioxide in which the arsenic content had been reduced to one part in $10^{8}-10^{9}$. These were purified by a process developed in the Laboratory and for which a patent application has been made. The process of purification has been studied by the use of radioactive arsenic.

Results of investigations on the production of fertilizers have been published and communicated to the industry. Further work in this field is confined to some more-specialized aspects, notably a study of the production of dicalcium phosphate. A wide range of equipment was shown in the microanalytical and spectrographic laboratories, including apparatus for the determination of active hydrogen by means of lithium aluminium hydride and a spectrum projection comparator.

One of the direct services of the Organic Group of the Laboratory to industrial and other laboratories is the supply of extremely pure organic compounds as standards for the calibration of mass spectrometers and for ultimate reference in other physical methods of analysis. Samples of thirty-six such standards 
were shown which are all available on request. Recent advances in chemotherapy have emphasized the potential importance of certain of the homologues of pyridine, and special attention has been given to the devising of methods for their recovery from crudetar bases, and to the establishment of suitable analytical techniques. Jointly with the Physics Division of the National Physical Laboratory, a study of the thermochemical properties of pyridine homologues has been started.

Preparative work of the Organic Group has included the synthesis of a supply of a cinnolylguanidine derivative (at the request of the Medical Research Council) for large-scale trial as a trypanocide, applications of the Kolbe-Schmidt reaction, and new syntheses of organic compounds containing isotopic carbon. Use of naphthalene labelled with isotopic carbon has been made in a method of estimating the naphthalene content of tar oils. The method would be suitable for use in studies of the effectiveness of naphthalene extraction in large-scale processes.

In the High Polymers Group, work on semipermeable membranes and ion-exchange resins was shown. The behaviour in non-aqueous systems of membranes prepared from polyvinyl alcohol is of outstanding interest. Using membranes of this type, polymer molecular weights from one million to two thousand have been determined by osmometry; in no case was there evidence of solute diffusion through the film (J. Chem. Soc., 3190; 1952). Statistical analysis of the results has shown that the relationship between osmotic pressure and concentration is best satisfied by the equation, $\pi=a C+b C^{2}$, where $a$ and $b$ are constants. Simple osmometers (capacity about $3 \mathrm{ml}$.) based on the Zimm-Meyerson design have been constructed for use with polyvinyl alcohol membranes. A novel form of reversed-phase partition chromatography was exhibited. Cross-linked polystyrene beads are allowed to swell in a carbon tetrachloride solution of the water-insoluble complexing agent, for example, dithizone. The swollen beads behave as selective absorbents and may be used for the recovery and separation of metals from aqueous acid solution.

Another service of the Chemical Research Laboratory is the supply of bacterial cultures of industrial and research interest. The National Collection of Industrial Bacteria, within the Microbiology Group, now maintains some six hundred strains, most of which are preserved in the freeze-dried state. Methods of classification and maintenance were demonstrated. Responsibility for the maintenance of 'official' cultures of antibiotic-producing organisms has recently been assigned to the National Collection by the United Nations World Health Organization.

Fundamental research on the sulphate-reducing bacteria has included a study of their oxidation of lactic, malic, pyruvic and other acids with sulphate as oxidizing agent, and the discovery of a 'sulphatefree' fermentation leading to ethanol and acetic acid. Work on their utilization of hydrogen has shown that this can result in the reduction of fumaric to succinic acid. Evidence for a co-hydrogenase, replaceable by methylene blue, has been obtained. Investigations on the microbiological production of sulphur and sulphide from sulphate are in progress at the Laboratory and at the Microbiological Research Department, (Ministry of Supply) at Porton. At the latter station, a continuous method of bacterial sulphate-reduction is being used; photographs and a diagrammatic flow-sheet of the apparatus used were exhibited.

\section{OBITUARIES}

Prof. C. H. Lees, F.R.S.

Prof. C. H. Lees passed away on September 25, at the age of eighty-eight. $\mathrm{He}$ was a man of great charm and endeared himself to friends and students. Lees possessed great patience, and he was not to be deviated from the course he had set himself by difficulties when carrying out a piece of research.

Born in Glodwick, Oldham, in 1864, he was a student at the Owens College, Manchester, becoming Berkeley Fellow in 1888. He then studied at the University of Strassburg.

In 1891 Lees was appointed senior assistant lecturer and demonstrator in physics in Owens College and became lecturer and assistant director of the Physical Laboratories of the University of Manchester in 1900. He left Manchester in 1906 to become professor in Queen Mary College, where he remained until 1930, retiring with the title of emeritus professor of physics in the University of London.

Although Lees's first claim to fame lies in the field of thermal conductivity measurements, he was a man of wide interests. In the years between the two World Wars, he had students carrying out research on problems of acoustics, elasticity, light, electricity, as well as heat. He contributed papers on A.C. bridges and on fluid flow through pipes. 'The technique he used in thermal conductivity measurements now finds a place in the text-books. His Phil. Trans. paper on the thermal conductivity of metals to low temperatures was the subject for 1908 of the Bakerian Lecture of the Royal Society.

Lees was an excellent committee man and for more than twenty years served on the Engineering Committee of the Food Investigation Board of the Department of Scientific and Industrial Research. $\mathrm{He}$ also served on the Safety in Mines Board.

Education was a topic of great interest to him and for a long period he served on the Kent Education Committee and the delegacy for managing Goldsmiths' College, London. For a time he was viceprincipal of Queen Mary College. He served as presi dent of the Physical Society and vice-president of the Institute of Physics.

His hobby was handicrafts, and up to within a few days of his death he occupied his time with carpentry.

In the passing of $\mathrm{C}$. H. Lees we mourn the loss of one of the 'old guard' of physics of the past generation and one of the greatest of friends.

Ezer Griffiths

\section{Prof. Millais Culpin}

IT is with regret that we record the death on September 14 of Prof. Millais Culpin at the age of seventy-eight. He was one of the brilliant group of psychiatrists revealed by the First World War.

He studied at the London Hospital and qualified M.R.C.S., L.R.C.P. in 1902, passing the F.R.C.S. three years later. It seemed that he was prepared for a surgical career and, indeed, he practised this for a time at Shanghai. However, when the War broke out, he joined the R.A.M.C. and became interested in war neurosis. Then he served in France during 1916 and 1917 as a surgeon, but still retained his psychiatric interest. At the end of this time he was asked by Aldren Turner to work in the Army neurological hospitals and there found ample material for research. His M.D. thesis in 1919 was devoted to his findings, 